\title{
Thermodynamic Control Enables trans-Selective Isomerization of Vicinal Diols via Iridium Photocatalysis
}
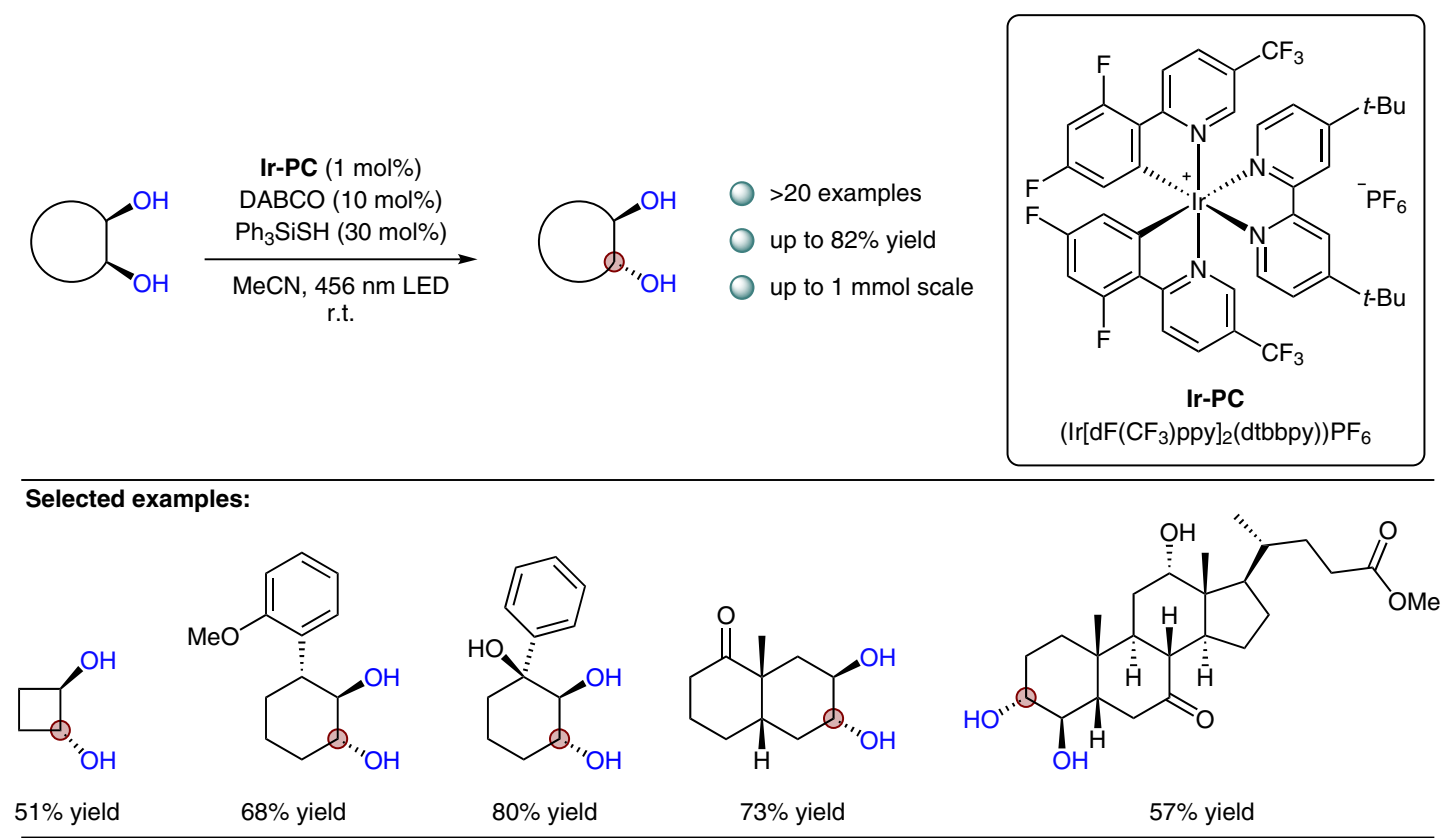

$68 \%$ yield

$80 \%$ yield

$73 \%$ yield

Key words

iridium catalysis

photocatalysis

diols

thermodynamic control

trans selectivity

\section{Carbohydrate-derived examples:}

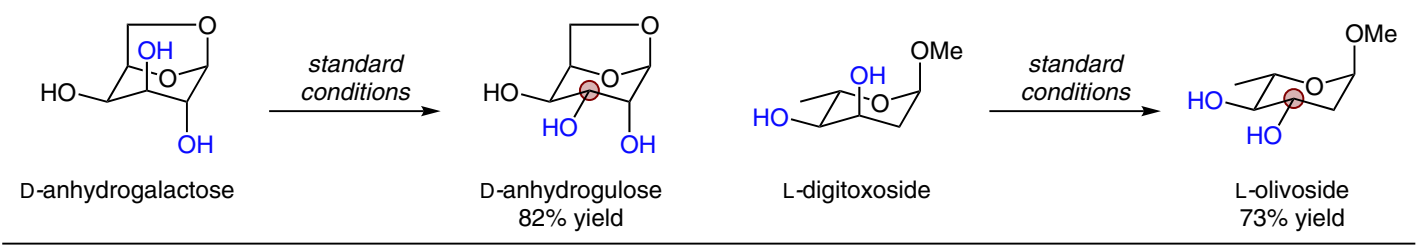

Example from mixture of cis-diols:

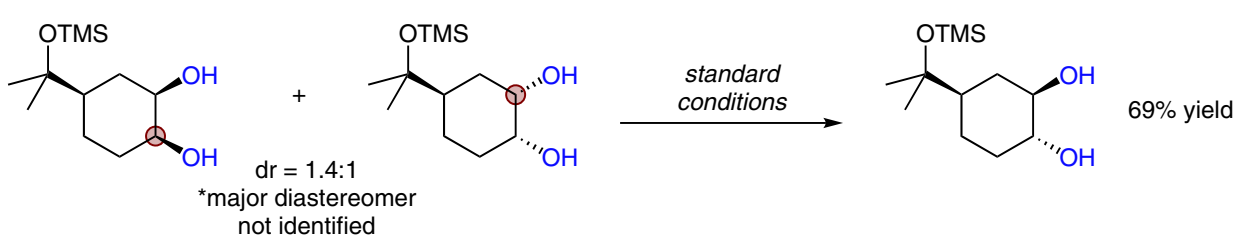

Significance: The Wendlandt group reports a selective catalytic isomerization of cis-1,2-diols to trans-diequitorial-1,2-diols via photoredox catalysis. The use of $\mathrm{Ph}_{3} \mathrm{SiSH}$ was found to be essential, as the nature of the silanethiol catalyst influenced the product distribution of the two isomers. The reaction was amenable to a variety of 1,2-diols and as well as mixtures of diastereomers, giving a single product isomer.
Comment: A series of mechanistic experiments revealed that, under the optimal conditions, the $\mathrm{H}$ atom abstraction and donation steps were mediated by the $\mathrm{Ph}_{3} \mathrm{SiSH}$ catalyst. The amine additive served as a base, not as a $\mathrm{H}$-atom abstractor. The authors conclude that since the $\mathrm{H}$-atom abstraction process is reversible, the equilibrium ratio represents the thermodynamic product distribution of the isomers. 